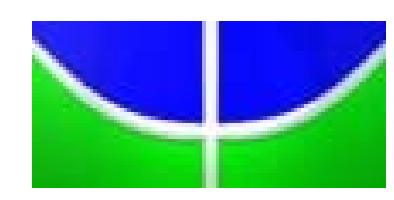

Universidade de Brasília

CET - Centro de Excelência em Turismo

Pós-graduação Lato Sensu

Curso de Especialização em Qualidades de Alimentos

\title{
VALIDAÇÃO DE UM INSTRUMENTO DE AVALIAÇÃO DO COMPORTAMENTO DO CONSUMIDOR ADULTO COM SOBREPESO/OBESIDADE FRENTE ÀS INFORMAÇÕES NUTRICIONAIS DOS RÓTULOS DE ALIMENTOS
}

\section{ALICIA MÓNICA LORIETO DÍAZ}


Universidade de Brasília

CET - Centro de Excelência em Turismo

Curso de Especialização em Qualidades de Alimentos

\title{
VALIDAÇÃO DE UM INSTRUMENTO DE AVALIAÇÃO DO COMPORTAMENTO DO CONSUMIDOR ADULTO COM SOBREPESO/OBESIDADE FRENTE ÀS INFORMAÇÕES NUTRICIONAIS DOS RÓTULOS DE ALIMENTOS
}

\author{
ALICIA MÓNICA LORIETO DÍAZ
}

Wilma Araújo, Doutora.

Professora Coordenadora
Wilma Araújo, Doutora

Professora Orientadora
Professor Examinador

Trabalho apresentado em cumprimento às exigências acadêmicas parciais do curso de pós-graduação lato sensu em Qualidades de Alimentos para a obtenção do grau de Especialista em Qualidades de Alimentos. 
LORIETO DÍAZ, Alicia Mónica

Validação de um instrumento de avaliação do comportamento do consumidor adulto com sobrepeso e obesidade frente às informações nutricionais dos rótulos de alimentos/Alicia Mónica Lorieto Díaz

Monografia - Curso de Qualidades de Alimentos Brasília - DF, março de 2006.

Área de Concentração: Nutrição Social

Orientador: Profa. Dra. Wilma Araújo

1. Instrumento de pesquisa 2. Comportamento do consumidor 3. Rotulagem Nutricional 
DEDICATÓRIA

Dedico esse trabalho monográfico a Joberto, meu esposo, por seu apoio incondicional em minha vida. 
À professora Wilma Araújo, pela orientação e sua constante presença para a realização do presente trabalho. Às nutricionistas colegas: Raquel, Renata, Rita, Karla e Karim, pelas contribuições na validação do instrumento. Ao corpo docente do curso, por suas contribuições nos conhecimentos da área de alimentos e pesquisa. Aos funcionários do CET, que colaboraram no desenvolvimento do dia-a-dia do curso. A Deus, por tudo que tenho e tudo que sou. 
"Dize-me o que comes, e eu te direi quem és." 


\section{RESUMO}

Em decorrência do aumento da prevalência de sobrepeso/obesidade e das doenças crônico-degenerativas associadas aos incorretos hábitos alimentares, a equipe de saúde, especialmente as nutricionistas, deve estimular uma escolha de alimentos saudáveis a partir de uma correta compreensão da composição química dos alimentos e ainda da Informação Nutricional apresentada dos rótulos de alimentos industrializados pelos consumidores que buscam, nos alimentos, a proteção da saúde. No entanto, as pesquisas, de modo geral, indicam uma deficiente compreensão da Informação Nutricional dos rótulos por parte dos usuários. Nesse contexto, esse trabalho propõe elaborar um instrumento de pesquisa validado para a coleta de dados sobre o comportamento do consumidor adulto com sobrepeso/obesidade, com relação à rotulagem nutricional de alimentos. A metodologia desse estudo é qualitativa e consta de uma primeira etapa de elaboração do instrumento de pesquisa e a segunda etapa é a aplicação de técnica de juízes e a análise semântica para sua validação. Pretende-se, no futuro, aplicar o instrumento validado e fazer a análise dos dados obtidos, para promover uma otimização das práticas alimentares saudáveis. Conclui-se que o formulário desenvolvido e validado para pesquisar os conhecimentos dos consumidores frente às informações nutricionais da rotulagem dos alimentos será a base para pesquisar e poder realizar mudanças nos hábitos alimentares da população alvo da pesquisa.

Palavras-chave: Instrumento de pesquisa; comportamento do consumidor; sobrepeso/obesidade; informações nutricionais; rotulagem nutricional. 


\begin{abstract}
Because to the raising of the overweight / obesity prevalence and of the chronic-degenerative diseases associated to the incorrect alimentary habits. The team of health, especially the nutritionists, should stimulate a choice of healthy foods starting from a correct understanding of the chemical composition of the foods and, still, of the presented Nutritional Information of the labels of foods industrialized by the consumers who looks for the foods the protection of the health. However, the researchers, in general, indicated a deficient understanding of the Nutritional Information of the labels on the part of the users. In this context, that work intends to elaborate a research instrument that can be validated for the collection of data about the adult consumer's behavior with overweight / obesity, regarding the nutritional labelarity of foods. The methodology of that study is qualitative and it consists of a first stage of elaboration of the research instrument and the second stage is the application of judges' technique and the semantic analysis for its validation. It is intended, in the future, to apply the validated instrument and to do the analysis of the obtained data, in order to promote an optimization of the healthy alimentary practices. We can conclude that the developed form and validated to research the knowledge of the consumers front to the nutritional information of the labels of the foods will be the base to research and to accomplish changes in the alimentary population's habits white of the research.
\end{abstract}

Word-keys: Instrument of research; the consumer's behavior; overweight / obesity; nutritional information; nutritional labels. 
1. INTRODUÇÂO. 1

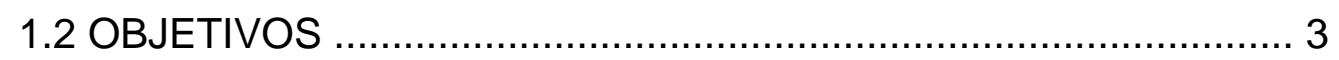

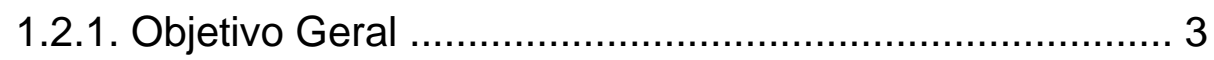

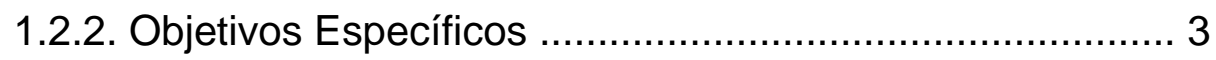

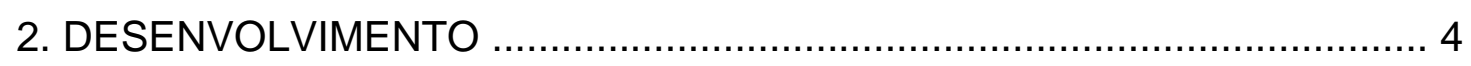

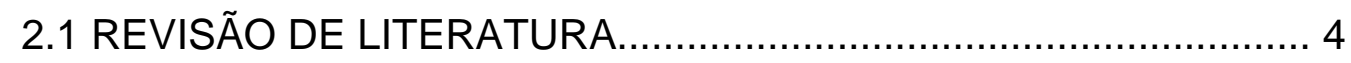

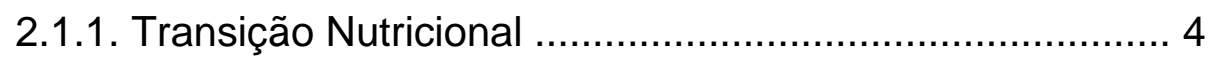

2.1.2. Sobrepeso e Obesidade ......................................... 6

2.1.3. Alimentação Saudável e Educação Nutricional ............. 11

2.1.4. Programas de Governo .................................... 13

2.1.5. Rotulagem Nutricional e Alimentos Para Fins Especiais 15

2.1.6.Instrumentos de coleta de dados.............................22

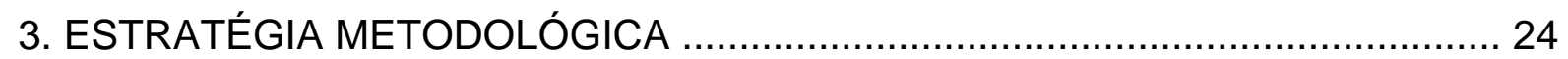

1.1. Primeira etapa: Concepção e desenvolvimento do instrumento

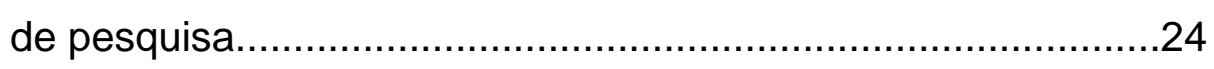

1.2. Segunda Etapa: Validação do instrumento pela técnica de juízes e aplicação do grupo focal...........................................26

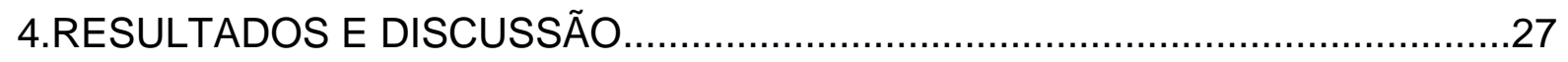

4.1. Etapa de elaboração do instrumento..................................27

4.2. Etapa de validação por técnica de juízes..............................27

4.3. Etapa de validação por grupo focal...................................28

5. CONSIDERAÇÕES FINAIS. 


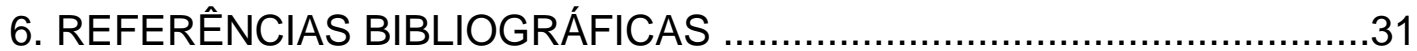

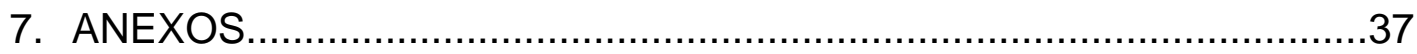

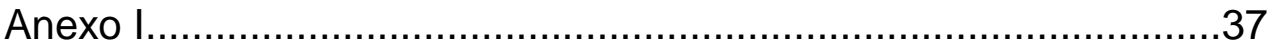

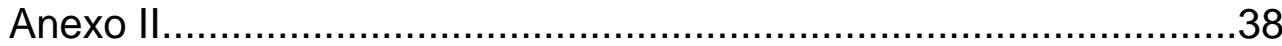

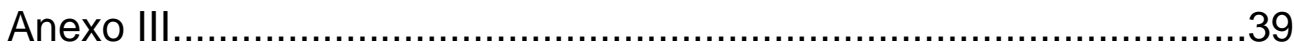

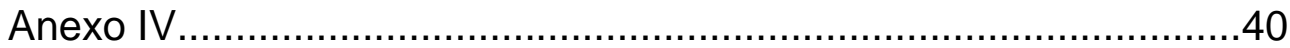

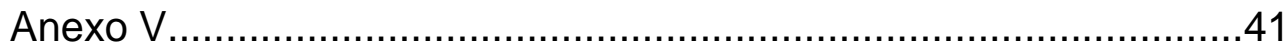


ABREVIATURAS

\begin{tabular}{|c|c|}
\hline ABESO & Associação Brasileira de Estudos da Obesidade \\
\hline ADA & American Dietetics Association \\
\hline ANVISA & Agência Nacional de Vigilância Sanitária \\
\hline CGPAN & Coordenação Geral de Políticas de Alimentação e Nutrição \\
\hline DF & Distrito Federal \\
\hline FDA & Food and Drugs Administration \\
\hline IBGE & Instituto Brasileiro de Geografia e Estatística \\
\hline INMETRO & Instituto Nacional de Metrologia \\
\hline MERCOSUL & Mercado Comum do Sul \\
\hline MS & Ministério da Saúde \\
\hline OMS & Organização Mundial de Saúde \\
\hline OPS & Organização Pan-americana de Saúde \\
\hline PAN & Política de Alimentação e Nutrição \\
\hline RDC & Resolução da Diretória Colegiada \\
\hline SVS & Sistema de Vigilância Sanitária \\
\hline UnB & Universidade de Brasília \\
\hline VD & Valor Diário \\
\hline
\end{tabular}




\section{INTRODUÇÃO}

Este trabalho propõe a validação de um instrumento para a coleta de dados sobre o comportamento do consumidor adulto com sobrepeso/obesidade frente às informações nutricionais dos rótulos de alimentos. Este instrumento é um elemento de suma importância na recuperação do estado de saúde do grupo a ser estudado.

Por ser a rotulagem nutricional um elo entre o consumidor e a indústria alimentícia, sua informação deve ser precisa e clara no que diz respeito aos dados que veicula para que o consumidor a receba de forma adequada.

A rotulagem nutricional dos alimentos é uma ferramenta de Educação Nutricional que deve ser empregada amplamente no combate aos distúrbios nutricionais. Fornecendo ao consumidor informações importantes para a composição de uma alimentação mais saudável e propiciando melhores escolhas alimentares desde o momento da compra dos alimentos.

Com base no fato de a transição nutricional se caracterizar no gradativo aumento da prevalência de sobrepeso e de obesidade em detrimento da redução da prevalência de desnutrição, forma-se um quadro preocupante para toda a sociedade, em especial para os profissionais da área de saúde e mais especificamente, para os nutricionistas (FELIPE \& cols., 2003).

Portanto, as doenças crônicas não transmissíveis representam atualmente um importante problema de saúde pública nas sociedades dos países em desenvolvimento, normalmente de alto custo social e de mais difícil prevenção.

Os hábitos alimentares apresentam-se como marcadores de risco para sobrepeso/obesidade, na medida em que o consumo elevado de calorias, de gorduras saturadas e carboidratos simples está somado ao baixo consumo de fibras 
e, assim, participam na etiologia da obesidade, das dislipidemias, dos diabetes e da hipertensão arterial (CASTRO \& cols., 2004).

Apesar da dificuldade em se mensurar o consumo alimentar e, conseqüentemente, de se comprovar especificamente o nutriente ou elemento da alimentação que está inadequado em termos quantitativos e qualitativos, vários pesquisadores têm conseguido demonstrar, por exemplo, que a mudança no padrão alimentar, mediante programas de orientação nutricional contribuiu para a prevenção de enfermidades cardiovasculares (FONSECA e cols.,1999; REIS \& COPLE ,1999, NEUMANN e cols., 2000).

Nesse sentido, a American Dietetics Association (ADA) faz uso de dados coletados em pesquisas para orientar a população americana em relação à rotulagem de alimentos. A ADA acredita que os rótulos são um instrumento de marketing que possibilitam a oportunidade de veicular elementos de promoção de uma nutrição adequada. Também promove o uso de claims (declaração de propriedades nutricionais), que estimulem o consumo de uma dieta variada com relação à qualidade e à quantidade de alimentos presentes na Pirâmide Nutricional Americana (FDA, 1997). Também, no Brasil, o Ministério da Saúde realizou um estudo para testar o grau de entendimento da informação contida nos rótulos dos alimentos pela população brasileira. Os dados obtidos indicam que grande parte dos entrevistados no estudo não interpretam corretamente as informações dos rótulos dos alimentos (COITINHO e cols., 2002).

Portanto, é fundamental o uso de um padrão de informação nutricional com terminologia adequada e facilmente compreensível pelo consumidor.

A partir da análise de alguns trabalhos, verifica-se que a rotulagem nutricional deve compor uma estratégia nacional de mobilização de todos os organismos 
públicos e privados, bem como de profissionais da saúde, no sentido de conduzir um programa de educação nutricional com o objetivo de prevenir o aumento de prevalência de obesidade e de outras doenças crônico-degenerativas. Um instrumento de pesquisa deve o aprimoramento sobre às informações nutricionais dos rótulos dos produtos alimentícios para que sejam claras e não confundam o consumidor. Portanto, o desenvolvimento de um instrumento específico para posterior aplicação se faz por pretender contribuir para que as entidades responsáveis revejam permanentemente as suas ações e para que se abdiquem às necessidades cotidianas do consumidor e, assim, esses possam melhor prevenir e cura as doenças crônicas não transmissíveis .

\subsection{Objetivos}

\subsubsection{Objetivo Geral}

Validar um instrumento de avaliação do comportamento do consumidor adulto com sobrepeso/obesidade frente às informações nutricionais dos rótulos de alimentos.

\subsubsection{Objetivos Específicos}

Elaborar uma ficha de avaliação antropométrica para caracterizar o público-alvo da aplicação do instrumento de pesquisa.

Desenvolver um questionário de avaliação do comportamento do consumidor, integrado por dados demográficos, de saúde, de compreensão das informações nutricionais dos rótulos do consumidor adulto com sobrepeso/obesidade.

- Aplicar a técnica de juízes para validar a ficha antropométrica e o questionário. 
Aplicar análise semântica ao instrumento a um grupo com as mesmas características dos possíveis entrevistados que, posteriormente, participarão da coleta de dados.

\section{DESENVOLVIMENTO}

\subsection{REVISÃO DE LITERATURA}

\subsubsection{Transição Nutricional}

Com a evolução dos tempos, desenvolveu-se a agricultura e a criação de animais. Em torno do alimento, formaram- se os primeiros grupos humanos. Como resposta às necessidades individuais a alimentação, tornou-se, progressivamente, elemento essencial na estrutura dos grupos humanos. No caminho dessa evolução, o mundo passou por uma série de transformações entre as quais os processos de industrialização, urbanização e mais recentemente a globalização. Com a conquista de novas oportunidades de trabalho, com o aumento da renda, a urbanização, a oferta de variedade de alimentos pelas indústrias e pelos serviços de alimentação, as sociedades mudaram seus hábitos alimentares e entraram em diferentes estágios de nutrição que têm sido chamados de transição nutricional. Essas mudanças em geral ocorrem paralelamente a um aumento na expectativa de vida da população e a diminuição das taxas de fertilidade. Também se associam com a transição epidemiológica, ou seja, com a diminuição da ocorrência de doenças infecciosas e doenças por carências nutricionais, sendo substituídas por um aumento de doenças coronarianas, alguns tipos de cânceres, aumento da prevalência de obesidade particularmente infantil e diabetes tipo I (POPKINS, 1994). 
Com a ocidentalização, as dietas ricas em carboidratos complexos e fibras alimentares são substituídas por dietas com maior proporção de gorduras totais, de gorduras saturadas e de açúcar. (BENGMARK, 1998).

Essas importantes mudanças nos hábitos alimentares ocorreram nos últimos cem anos. Apesar de as pessoas precisarem hoje de muito menos energia devido a redução generalizada de atividades físicas, o consumo de gordura aumentou em $20 \%$ de energia consumida para aproximadamente $50 \%$ na atualidade. Calcula-se que a dieta, na era paleolítica, continha de 5 a 10 vezes mais fibras que a dieta ocidental contemporânea.

No Brasil, a tendência de redução dos índices de desnutrição e o aumento nos índices de obesidade têm sido evidenciados. Nos últimos anos, observam-se rápidas transformações demográficas, nutricionais, econômicas e epidemiológicas. A transição demográfica vem ocorrendo em decorrência da industrialização, da urbanização, da modernização tecnológica e da globalização (BATISTA FILHO E RISSIN, 2003).

Segundo Tagle, 1998, os fatores que influenciam nas mudanças de consumo alimentar são complexos e incluem:

- mudanças na renda familiar;

- migração rural-urbana;

- terceirização dos alimentos que implicam serviços incorporados (alimentos semipreparados e preparados, refeições feitas fora de casa);

- exposição à publicidade comercial.

No entanto, uma nova agenda começa a se sobrepor, dado que as populações começam a sofrer os problemas dos excessos alimentares. Deve-se, 
antes, promover uma dieta que traduza uma alimentação saudável, do que dietas específicas para desnutrição ou obesidade.

A taxa de urbanização de 81,2\% em 2000 mostra um importante aumento no índice de urbanização, o mais rápido processo nos últimos 50 anos, confirmando a situação atual de país urbano (IBGE , 2004a.).

Portanto, o efeito das alterações demográficas brasileiras com os avanços tecnológicos no crescimento da expectativa de vida em um progressivo envelhecimento da população, gerando novas demandas para o sistema de saúde. A expectativa de vida no ano 2000 alcançou a média de 67,2 anos (IBGE, 2004b.).

Também se observa um aumento da morbidade e mortalidade por doenças crônicas não-transmissíveis em detrimento das doenças infecciosas (CGPAN, 2004).

Pode-se observar uma maior participação da mulher no mercado laboral estando em 48,9\% (IBGE, 2003). Infere-se que as mulheres estão assumindo um papel relevante como provedoras de renda, além de acumularem a esse papel a função doméstica (IBGE, 2003).

A globalização e o avanço tecnológico também foram responsáveis pelo novo perfil da sociedade que elevou o número de horas em atividades intelectuais em detrimento das atividades físicas. As ocupações de trabalho envolvem menor gasto energético que nos tempos da economia rural (RIZZOLO, 2005).

\subsubsection{Sobrepeso e Obesidade}

A obesidade é a alteração do estado nutricional acompanhado por um aumento marcante do número de células adiposas. Não se sabe se o estímulo para esse aumento de número de células adiposas é nutricional, endócrino, 
comportamental, genético ou alguma associação dessas combinações (COPPINI E WAITZBERG, 2000).

A provável fisiopatologia da obesidade envolve: comer mais; queimar menos calorias; fazer gordura mais facilmente e oxidar menos gorduras (HALPERN, 2002).

A Organização Mundial de Saúde (OMS) reconhece a obesidade como uma doença que já atinge proporções epidêmicas no mundo todo, sendo, portanto caracterizada como uma pandemia. Os epidemiologistas americanos estimam que, se mantidos os padrões atuais de aumento de prevalência, 100\% da população americana será obesa no ano 2025.

No Brasil, estamos vivenciando a chamada transição nutricional. Dados de 1991 revelaram que $8,5 \%$ da população é desnutrida enquanto 32\% tem sobrepeso (IMC 25-30) e 8\% são obesos (IMC>30). Tal aumento foi observado em ambos os sexos e em todas as classes sociais. O único segmento da população que apresentou queda da prevalência foi o de mulheres na região Sudeste, em particular as pertencentes ao quarto quartil de renda, provavelmente pelo melhor nível de informação a que tiveram acesso. Já a prevalência de obesidade na adolescência correlaciona-se com o grau de riqueza na região, sendo prevalente nas regiões mais desenvolvidas e urbanizadas (Sudeste e Sul). É maior em meninas que meninos em todas as regiões brasileiras.

Portanto, devido ao aumento mundial e a importância da obesidade pelas doenças que ela pode acarretar, a OMS criou uma força-tarefa internacional para a obesidade - IOTF (International Obesity Task Force) com o objetivo de conscientizar a população e ajudar os profissionais da área de saúde a tratar eficientemente o desafio da obesidade na prática clínica diária. 
A origem da obesidade é o aumento do peso corporal devido a um excesso de tecido gorduroso, resultado da interação de vários fatores, tais como os genéticos e os ambientais. Em geral, os pacientes obesos experimentam grandes repercussões psicológicas, tais como baixa auto-estima, quadros depressivos e ansiosos, que freqüentemente são agravados pelo massacre exercido pela mídia para se tentar obter um padrão de beleza em que o peso tido como ideal fica abaixo dos níveis aceitáveis como normais. (NEGRATO, 2003)

Em geral, apresentando associações de doenças e distúrbios ligados ao excesso de peso e os pacientes obesos têm uma diminuição de suas expectativas de vida e também uma piora acentuada em sua qualidade.

Para realizar o diagnóstico, é feita avaliação do Índice de Massa Corporal ou IMC, índice recomendado inclusive pela OMS. Esse índice é calculado dividindo-se o peso do paciente em quilogramas $(\mathrm{kg})$ pela sua altura em metro ao quadrado $\left(\mathrm{m}^{2}\right)$. O valor acima obtido estabelece o diagnóstico da obesidade e caracteriza, também, os graus de riscos associados à mesma.(tabela 1)

Tabela 1: Classificação dos tipos de obesidade segundo o IMC.

\begin{tabular}{|c|c|c|}
\hline IMC $\left(\mathrm{kg} / \mathrm{m}^{2}\right)$ & Grau de risco & Tipo de obesidade \\
\hline 18 a 24,9 & Peso saudável & Ausente \\
\hline 25 a 29,9 & Moderado & Obesidade grau 1 \\
\hline 30 a 34,9 & Alto & Obesidade grau 2 \\
\hline 35 a 39,9 & Muito alto & Obesidade grau 3 (mórbida) \\
\hline 40 ou mais & Extremo & \\
\hline
\end{tabular}

Fonte: Negrato,2003.

Segundo Negrato (2003), a obesidade pode ser classificada de acordo com o tipo de deposição da gordura em:

1. obesidade difusa ou generalizada; 
2. obesidade andróide, troncular ou centrípeta, que está associada com maior deposição de gordura na região abdominal e se relaciona intensamente com alto risco para ocorrência de doenças metabólicas e cardiovasculares;

3. obesidade ginecóide, na qual a deposição de gordura se dá predominantemente na região do quadril. Está associada a um maior risco de artrose e varizes de membros inferiores.

Com base nessa classificação, criou-se um índice denominado relação cintura-quadril que é obtido pela divisão da circunferência da cintura abdominal pela circunferência do quadril do paciente. De uma forma geral, aceita-se que existem riscos metabólicos quando a relação cintura-quadril for maior do que 0,9 no homem e 0,8 na mulher. A simples medida da circunferência abdominal também já é considerada um indicador de risco para complicações da obesidade, definida de acordo com o sexo do paciente. A tabela 2 apresenta os valores limites de circunferência abdominal associados ao desenvolvimento de complicações relacionadas á obesidade.

Tabela2: Circunferência de cintura de acordo com o sexo.

\begin{tabular}{|c|c|c|}
\hline & Risco aumentado & $\begin{array}{c}\text { Risco muito } \\
\text { aumentado }\end{array}$ \\
\hline Homem & $94 \mathrm{~cm}$ & $102 \mathrm{~cm}$ \\
\hline Mulher & $80 \mathrm{~cm}$ & $88 \mathrm{~cm}$ \\
\hline
\end{tabular}

Fonte: Negrato, 2003.

Também a gordura corporal pode ser estimada por meio da medida das pregas cutâneas, do cálculo da bioimpedância, do ultra-som e da ressonância nuclear magnética. Essas últimas técnicas são utilizadas apenas em alguns casos de pesquisa clínica e não como método de rotina.

A obesidade pode ser classificada de acordo com suas causas as quais são:

- obesidade por distúrbio nutricional; 
- obesidade por inatividade física;

- obesidade secundária a alterações endócrinas;

- obesidades secundárias a distúrbios não endócrinos;

- obesidade de causa genética.

A avaliação do paciente obeso deve incluir anamnese e exame clínico detalhados, e de acordo com o resultado dessa avaliação, o médico irá investigar as possíveis causas do distúrbio. Sendo, às vezes, necessária a realização de alguns exames específicos.

Portanto, o tratamento da obesidade envolve necessariamente uma reeducação alimentar, ou o aumento da atividade física e, eventualmente, o uso de algumas medicações, dependendo da situação de cada paciente. Em alguns casos pode ser indicada uma abordagem de mudança comportamental, envolvendo avaliações psicológicas e até psiquiátricas. Nos casos de obesidade secundária a outras doenças, o tratamento deve inicialmente ser dirigido para a doença básica que esteja causando o distúrbio.

Em definitivo, a reeducação alimentar é fundamental, uma vez que, por meio dela, reduziremos a ingesta calórica total e o acúmulo calórico excessivo decorrente dela.

A obesidade é uma doença de difícil controle, com altos percentuais de insucessos terapêuticos e de recidivas, podendo apresentar sérias repercussões orgânicas e psicossociais, especialmente nas formas mais graves (BERNARDI, 2005).

Portanto, conclui-se que o tratamento da obesidade envolve, necessariamente, um acompanhamento multiprofissional, com mudanças no estilo de vida e também de comportamento. 


\subsubsection{Alimentação Saudável e Educação Nutricional}

Também o crescimento da atenção e do interesse por uma alimentação saudável tem-se traduzido em diversas ações das indústrias e dos governos na busca da melhoria do estado nutricional (DUTRA, DE OLIVEIRA E MARCHINI, 1998).

Em seu estudo epidemiológico, Cândido e Campos, (1995) demonstram a correlação entre estilo de vida e condições de saúde. A pesquisa sobre hábitos alimentares caracteriza atenção cada vez maior em alimentos ricos em carboidratos, colesterol, ácidos graxos saturados, à medida que se confirma a correlação dieta por doenças crônico-degenerativas.

Atualmente, o sobrepeso e obesidade constituem a doença nutricional que mais aumenta no mundo apresentando proporções de pandemia. Este cenário está associado a hábitos alimentares e sedentarismo, e é secudando estreitamente às doenças crônicas como diabetes, hipertensão e intercorrências cárdio-circulatórias de maior gravidade.

Para a ciência, a qualidade da alimentação dá-se por seu valor nutricional ou atributos funcionais orientado ao que deve ser restringido ou ter seu consumo aumentado, para diminuir os riscos de doenças crônico-degenerativas ou auxiliar na recuperação ou manutenção da saúde (GARCÍA, 2000).

A promoção de uma alimentação saudável é um dos desafios para os profissionais da saúde neste início de século. 
Segundo ORNELLAS (1995), para que o processo de alimentação atinja seus objetivos diferentes aspectos devem ser observados: valor nutricional, qualidade higiênico-sanitária, características digestivas e sensoriais e aspectos econômicos. Mais recentemente, vem-se discutindo também a questão da identificação social dos alimentos (FLANDRIN E MONTANARI, 1998).

Portanto, a composição da refeição depende de diferentes fatores, dentre os quais a racionalidade dietética que implica novos conhecimentos, escolha de produtos segundo esse critério, aprendizagem de procedimentos culinários alternativos, disponibilidade financeira e de tempo para executar novos pratos entre outros (CARRASCO apud GARCÍA, 2000).

A transmissão desse conhecimento e sua adaptação ao perfil social e alimentar de cada indivíduo é atividade que compete ao nutricionista como regulamenta o artigo 3, VII, da Lei no 8.234 de 1991 (BRASIL, 1991).

A partir da década dos 80, com a consolidação dos cursos de Nutrição no Brasil, a comprensão do público a respeito de a relação entre dieta e saúde tem aumentado sensivelmente .

Nesse contexto, a educação nutricional tem como objetivo difundir os conhecimentos práticos da ciência da Nutrição para que as pessoas, independentemente de sua classe social, conheçam o valor nutricional dos alimentos e as técnicas adequadas de utilização a fim de que esses alimentos possam suprir as necessidades orgânicas.

O objetivo da educação nutricional, a longo prazo, é habilitar os indivíduos a tomar decisões sobre nutrição de acordo com o conhecimento científico, assim como com seus próprios objetivos, valores e estilo de vida. Deve-se educar o indivíduo e a família sobre hábitos adequados de alimentação, consumo de alimentos de acordo 
com a idade, sexo, atividade física e estado fisiológico. É preciso também erradicar os hábitos sedentários, estimulando as atividades esportivas individuais, na comunidade e na escola. (MARTINS E ABREU, 1997; SCHWARTZMANN, 1998).

São necessárias medidas de prevenção e resgate do comportamento alimentar tradicional saudável, além da adesão a novos hábitos que sejam aprendidos desde a infância para que haja a formação de indivíduos saudáveis que consigam viver com qualidade de vida e, portanto, possam contribuir muito mais para a construção da sociedade.

\subsubsection{Programas de Governo para a promoção de práticas alimentares e estilos de vida saudáveis.}

Dado o impacto sócio-econômico que têm os problemas derivados do sobrepeso e obesidade, a intervenção do Estado por meio de políticas é necessária. Portanto, essas estratégias devem minimizar os riscos de desnutrição e da subnutrição como a anemia, o bócio endêmico e hipovitaminose $A$ e também diminuir os fatores de risco para a ocorrência futura de sobrepeso e obesidade (MENEZES e cols., 2004).

Outro fator relevante a ser considerado nas estratégias de Governo é que as medidas de controle de sobrepeso e obesidade adotadas não contribuam para o aparecimento de transtornos alimentares como anorexia e bulimia (MENEZES e cols., 2004).

O Instituto Brasileiro de Defesa do Consumidor, diante da problemática e da realidade brasileira, vem dando ênfase aos direitos básicos do consumidor: direito à informação e o direito de escolha, alicerçados pelo artigo $6^{\circ}$ do Código do Consumidor (BRASIL, 1990). Apesar de o Código de Defesa do Consumidor ser 
insuficientemente detalhado no sentido de estabelecer padrões específicos para a apresentação, conteúdo e formato mais adequados aos diversos tipos de informações relacionadas com a rotulagem dos alimentos (FERRAZ, 2001).

Em 1999, o Ministério da Saúde criou a Política Nacional de Alimentos e Nutrição (PNAN), o programa responsável pelo direcionamento de todas as ações da coordenação geral de políticas de alimentação e nutrição do Ministério.

A PNAN tem duas diretrizes relacionadas ao combate da obesidade e outras enfermidades crônicas não-transmissíveis. A primeira se refere à promoção de prática alimentar e estilo de vida saudáveis, que incentiva a saúde, e a segunda é a prevenção e combate dos distúrbios nutricionais e doenças associadas que constituem condutas de prevenção e melhora das patologias (PNAN, 2000).

Portanto, a regulamentação da rotulagem nutricional obrigatória para produzir alimentos foi um avanço primordial do Ministério da Saúde devido ao fato de a rotulagem nutricional garantir o direito de informação sobre o conteúdo do alimento e permite tomar decisões mais acertadas. Para tanto, desenvolveram-se dois manuais: um Manual de Orientação às Indústrias que é um apoio técnico para as indústrias de alimentos e o segundo é um Manual de Orientação ao Consumidor que serve para facilitar a compreensão dos rótulos por parte dos consumidores. Mas esse manual não está ao alcance de todos os níveis da população, pois ele tendo pouca divulgação.

No final do ano 2003,ANVISA publicou a RDC no 359/03 - Regulamento Técnico Porções de Alimentos Embalados Para Fins de Rotulagem Nutricional que indica a importância do consumo de porções moderadas de alimentos a qual se fundamenta na base da pirâmide alimentar. Diante das dificuldades para entender o significado de algumas expressões usadas nos rótulos como: porção, composição 
química, diet e light (MENEZES e cols., 2004). A ANVISA em convênio com o Departamento de Nutrição da UnB vem desenvolvendo estratégias de educação nutricional por meio da compreensão da informação dos rótulos nutricionais e que o consumidor possa fazer melhores escolhas de sua alimentação.

Dentro desta mesma linha pedagógica, existe o Programa de Merenda Escolar que é desenvolvido nas escolas públicas do Brasil, numa tentativa de estimular as crianças a adotarem hábitos alimentares saudáveis (COUTINHO e cols., 2002).

O material didático voltado para a alimentação da população de crianças são os guias alimentares da população brasileira. Elas promovem o consumo de frutas e hortaliças no Brasil, evitando a desnutrição e obesidade (LESSA, 2005).

A partir do documento da estratégia mundial para a alimentação saudável, atividade física e saúde, foram estabelecidas as recomendações para a dieta: limitar da ingestão calórica de origem lipídica, substituir gorduras saturadas e gorduras trans por gorduras insaturadas, aumentar o consumo de frutas e hortaliças, cereais integrais, legumes e similares, limitar a ingestão de açúcares simples, limitar a ingestão de sal e buscar o equilíbrio energético para a manutenção de um peso adequado (CGPAN, 2004).

\subsubsection{Rotulagem Nutricional}

O conceito de rotulagem de alimentos e bebidas faz parte do conjunto de estratégias que vêm sendo adotadas pelo governo federal para atenuar, reverter ou até prevenir doenças crônicas-não transmissíveis. A legislação atual pode ser considerada o resultado de evolução da Política de Alimentação e Nutrição Brasileira das últimas décadas, o que explica a necessidade de se consultar inúmeros 
regulamentos para a elaboração de rótulos de produtos alimentícios. Em 2002, entram em vigor a resolução RDC 259/02, que aprova o Regulamento Técnico sobre Rotulagem de Alimentos Embalados, revogou a Portaria $n^{\circ} 42 / 98$, atualizando as regras para a rotulagem geral de alimentos e adequando-as á Resolução GMC $n^{\circ} 06 / 94$ e $n^{0} 21 / 02$.

Além de ser obrigatória, a rotulagem deve ser entendida como informação importante que pode auxiliar tanto o consumidor na escolha do alimento em benefício de sua saúde e do seu bem-estar, como também os fabricantes, uma vez que ela permite a divulgação de alegações de propriedades nutricionais.

A importância da rotulagem nutricional dos alimentos para a promoção da alimentação saudável é destacada em grande parte dos estudos e pesquisas que envolvem a área da nutrição e sua relação com estratégias para a redução do risco de doenças crônicas.

Nesse sentido, o uso das informações nutricionais obrigatórias nos rótulos de alimentos e bebidas embaladas está regulamentado no Brasil desde 2001. A Resolução $n^{\circ} 40$ foi revogada pela Resolução RDC/ANVISA n³60 do 23.12.03 e harmonizada no MERCOSUL. Os alimentos fabricados a partir de 01.08 .06 devem indicar a Rotulagem Nutricional de acordo com o estabelecido no Mercosul.

O propósito foi elaborar um regulamento único que atendesse aos países integrantes do Mercado Comum do Sul - Mercosul, tornando imprescindível a revisão das normas brasileiras e sua adequação com relação ao avanço deste tema no contexto mundial.

Devido a demanda crescente da sociedade por informações confiáveis acerca dos produtos exige esforço do governo e do setor produtivo para implantação de uma efetiva rotulagem nutricional de alimentos. 
Por definição, a rotulagem segundo Miyazaki (2005) é toda a informação descritiva ou gráfica constante da embalagem de um alimento. Para facilitar a aplicação das normas, a legislação de rotulagem está dividida em: rotulagem geral e rotulagem nutricional.

i) A rotulagem geral obriga a indicação dos seguintes itens na embalagem dos alimentos:

a. denominações técnicas de venda do produto;

b. conteúdo líquido;

c. lista de ingredientes;

d. país de origem;

e. identificação do lote e prazo de validade; e

f. modo de preparo e uso do alimento, quando necessário.

É preciso lembrar que a rotulagem nutricional tem como objetivo informar ao consumidor as propriedades nutricionais de um produto. As propriedades nutricionais de um alimento podem ser indicadas por meio de duas informações principais a serem mencionadas:

a. a rotulagem nutricional;

b. a informação nutricional complementar, classificada em:

- declaração de nutrientes;

- alegação de propriedades funcionais; e

- alegação de propriedade de saúde.

A partir desses princípios, a rotulagem nutricional é uma relação ou listagem coordenada dos nutrientes de um alimento, sendo que no Brasil os nutrientes obrigatórios para a declaração são: valor energético, carboidratos, proteínas, 
gorduras totais, gorduras saturadas, gorduras trans, fibras alimentares, sódio, VD com base em uma dieta de 2.000 calorias.

Pode-se afirmar que a informação nutricional complementar (declaração de propriedades nutricionais ou alegação "claim") é qualquer representação que afirme, sugira ou implique que um produto possui propriedades nutricionais particulares (MIYAZAKI, 2005).

A declaração pode ser feita, especialmente, mas não somente, em relação ao seu valor energético e seu conteúdo de proteínas, gorduras, carboidratos e fibra alimentar, bem como seu conteúdo de vitaminas e minerais. Exemplo de informação complementar, são as expressões "light, low, free", cujos atributos estão estabelecidos na Portaria n 27, de 13.01.98, da Secretaria de Vigilância Sanitária do Ministério da Saúde (MIYAZAKI, 2005).

Em outra abordagem, as alegações de propriedade funcional e ou de saúde são aquelas que fazem referências à manutenção geral da saúde, ao papel fisiológico dos nutrientes e não nutrientes e à redução de riscos à doença. Não são permitidas alegações de saúde que façam referência à cura, tratamento ou prevenção de doenças (MIYAZAKI, 2005).

ii) A rotulagem nutricional tornou-se obrigatória no Brasil para todos os alimentos e bebidas, exceto as alcoólicas e águas minerais, através da Resolução / ANVISA $n^{\circ}$ de 40, de 21 de março de 2001. Em 2003 a Resolução $n^{0} 40$ foi revogada pela Resolução RDC/ANVISA no 360 de 23.12.03 harmonizada no Mercosul. Os alimentos fabricados a partir de 01.08 .06 deverão indicar a rotulagem nutricional de acordo com o estabelecido no Mercosul.

As quantidades de valor energético, carboidratos, proteínas, gorduras totais, gorduras saturadas, gorduras trans, fibras alimentares, sódio e VD com base em 
uma dieta de 2.000 calorias devem ser apresentadas obrigatoriamente nos rótulos dos alimentos e das bebidas embaladas. Além dessas quantidades, o percentual do valor diário (\%vd) também deve ser indicado. Esse percentual representa o quanto o valor calórico, e a quantidade do nutriente ou componentes presentes na porção de referência do alimento contribui para uma dieta de 2.000 calorias diárias. Alguns alimentos poderão ter suas declarações de nutrientes simplificadas (MIYAZAKI, 2005).

Em vista da influência da rotulagem sobre os consumidores, é fundamental não apenas regulamentar alimentos para fins especiais, mas fazer a indústria de alimentos cumprir a legislação. Na opinião de Shank e Carson, o melhor sistema para proteger a saúde do consumidor envolve dois níveis de controle: a) de responsabilidade da indústria, a produção de alimentos seguros; b) de responsabilidade das agências governamentais, o monitoramento que assegure que a indústria exerce sua função.

Afirmando que a rotulagem é o meio pelo qual se estabelece um canal de comunicação entre empresas produtoras de alimentos e consumidores que desejam informações sobre os produtos que compram. Entre outros objetivos, a regulamentação da rotulagem procura proteger os consumidores de declarações abusivas ou infundadas que possam induzi-los a erros (ARAÙJO, 2001).

Portanto a rotulagem e indicações nutricionais em alimentos industrializados, em especial de alimentos para fins especiais, são fundamentais para orientar o consumidor quanto à qualidade do produto e as opções de escolha. A legislação brasileira normatiza padrões de identidade e qualidade para esses alimentos e critérios para a rotulagem. 
A Portaria $n^{0}$ 29, da SVS/MS (13.01.1998), fixou a identidade e as características mínimas de qualidade a que devem obedecer os alimentos para fins especiais. Segundo a portaria, alimentos para fins especiais são alimentos especialmente formulados ou processados, nos quais se introduzem modificações no conteúdo de nutrientes, adequados à utilização em dietas diferenciadas e/ou opcionais, atendendo às necessidades de pessoas em condições metabólicas e fisiológicas específicas. Também a portaria divide alimentos para fins especiais em 3 grupos principais: para dietas com restrição de nutrientes; para ingestão controlada de nutrientes; e para grupos populacionais específicos. Atualmente, revogadas pelas Resoluções RDC n³60/02 e n²59/02.

Cumpre destacar que a Portaria $n^{\circ} 29$ determina que os alimentos para fins especiais contenham no painel principal a designação do alimento, conforme legislação específica, seguida da finalidade a que se destina, em letras da mesma cor e tamanho. O termo diet pode (opcionalmente) constar em alimentos empregados exclusivamente para: controle de peso; dietas de ingestão controlada de açúcares; e dietas com restrição de nutrientes. Nos demais painéis, devem constar (obrigatoriamente) modo de preparo, quando o alimento não estiver à venda pronto para consumo, e cuidados de conservação e armazenamento antes ou depois de abrir a embalagem, se for o caso. A portaria inclue, também, que alimentos para fins especiais contenham em negrito e em destaque: "Diabéticos: contém (especificar mono e/ou dissacarídio)", quando forem alimentos para dietas com restrição de nutrientes (alimentos para dietas com restrição de carboidratos, para dietas com restrição de gorduras, para dietas com restrição de proteínas, para dietas com restrição de sódio) alimentos para ingestão controlada de nutrientes, alimentos para controle de peso, alimentos para praticantes de atividades físicas e 
alimentos para dietas com ingestão controlada de açúcares contiverem mono e/ou dissacarídeos (glicose, frutose e/ou sacarose), conforme o caso; a informação: "Contém fenilanalina", para alimentos em que haja adição de aspartame; a informação: "Este produtos pode ter efeito laxativo", para alimentos cuja previsão razoável de consumo resulte na ingestão diária superior a $20 \mathrm{~g}$ de manitol, $50 \mathrm{~g}$ de sorbitol, $90 \mathrm{~g}$ de polidextrose ou de outros polióis que possam ter efeito laxativo;e a orientação "Consumir preferencialmente sob orientação de nutricionista ou médico". A orientação constante dos regulamentos específicos das classificações dos Alimentos para Fins Especiais deve prevalecer quando diferir desta orientação. (ARAÚJO, 2001).

Por definição, os Alimentos para Controle de Peso (Portaria SVS/MS 30/98): são os alimentos especialmente formulados e elaborados de forma a apresentar composição definida, adequada a suprir parcialmente as necessidades nutricionais do indivíduo e que sejam destinados a propiciar redução, manutenção ou ganho de peso. Classificam-se em: alimentos para redução ou manutenção de peso por substituição parcial das refeições ou para ganho de peso por acréscimo às refeições e alimentos para redução de peso por substituição total das refeições.(MIYAZAKI, 2005)

O instrumento de avaliação do entendimento da informação nutricional dos rótulos por uma população com sobrepeso/obesidade pretende pesquisar o entendimento dos termos específicos. 


\subsubsection{Instrumentos de coleta de dados}

Segundo Moron (1998), os instrumentos de coleta de dados têm a função de ligar o que o pesquisador quer saber com a realidade, ou seja, os instrumentos de pesquisa são utilizados para "ler a realidade".

Um instrumento de coleta é o questionário, que faz uma descrição quantitativa da pesquisa. O questionário deve responder ao objetivo de pesquisa. Portanto, as perguntas devem ser claras e precisas, considerando o tipo de entrevistado (FREITAS, 2000).

Podemos classificar o questionário, Richardson (1985), segundo o tipo de perguntas feitas aos entrevistados e o modo de aplicação dele. Pelo tipo de perguntas, os questionários são de perguntas abertas ou fechadas. As perguntas fechadas se aplicam para dar respostas fixas, com alternativas dicotômicas (sim não; verdadeiro - falso), tricotômicas (sim - não - não sabe) ou alternativas múltiplas hierarquizadas (nunca - ás vezes - sempre). Estes tipos de perguntas facilitam o preenchimento do questionário. As perguntas, não devem ser fechadas quando são para medir opiniões, fatores, motivos, segundo Richardson (1985).

Os questionários de perguntas abertas devem ser utilizados quando o pesquisador vai estudar um tema pontual, mas os resultados são de difícil codificação e mais complexos para serem respondidos (RICHARDSON,1985). É uma ferramenta bastante usada para que o entrevistado tenha mais liberdade para se expressar; nela se acrescenta a opção "outras" entre as alternativas e se especifica qual é.

O modo de aplicação do questionário pode ser de contato direto por correio, pela internet, pelo telefone, etc. O método de contato direto é realizado por entrevistador ou pessoas que sejam treinadas por ele. O contato direto permite 
esclarecer qualquer dúvida que se apresente ao entrevistado, enquanto no método indireto (correio, internet) o questionário e as instruções são enviados para as pessoas previamente selecionadas. Este método tem a vantagem de incluir maior número de pessoas de diferentes pontos geográficos.

O formulário é uma lista formal, catálogo ou inventário destinado á coleta de dados, cujo preenchimento é feito pelo próprio investigador. Assim o que caracteriza o formulário é o contato face a face entre pesquisador e informante. A vantagem do formulário é que ele é passível de ser aplicado em qualquer segmento da população em virtude da possibilidade de o pesquisador esclarecer duvidas e elucidar significados. (AKUTSU, 2005)

A etapa seguinte, que é a validação do instrumento, serve para dar validade científica ao instrumento de avaliação em função do modelo de vida da população a ser entrevistada.

Para a validação desse trabalho, utilizou se - a técnica de juízes e o grupo focal.

A técnica de juízes é feita por cinco especialistas em rotulagem nutricional e tem por finalidade considerar a clareza, a completude e a pertinência do questionário em relação ao objetivo geral do trabalho, segundo Freitas e cols., (2000). O pré-teste é a aplicação prévia do questionário a um grupo que seja representativo das características da população a ser pesquisada e tem por finalidade refinar o instrumento e testar a compreensão dos termos utilizados no questionário (RICHARDSON, 1985).

Outra técnica usada para validação dos instrumentos de pesquisas qualitativas é o grupo focal. Essa técnica é realizada numa amostra do grupo final que vai ser pesquisado. A finalidade de sua aplicação é fazer um levantamento das 
opiniões, das percepções, dos sentimentos, do comportamento do entrevistado com respeito ao tema a pesquisar (FREITAS e OLIVEIRA, 2000).

\subsection{ESTRATÉGIA METODOLÓGICA}

O método de pesquisa deste trabalho foi de tipo qualitativo, sendo aplicada a técnica de juízes e o grupo focal para validação do instrumento. Tanto a ficha antropométrica como o questionário têm o propósito de identificar as atitudes e opiniões dos entrevistados num momento determinado, sendo por esta condição um estudo de corte transversal.

\subsubsection{Primeira etapa - Concepção e elaboração do instrumento}

Esta primeira etapa do projeto constitui-se na concepção e elaboração do instrumento para a coleta de dados para estudar o comportamento do consumidor em relação à rotulagem nutricional .

Para sua elaboração, considerou-se que 0 consumidor alvo tem sobrepeso/obesidade que provavelmente tenha dificuldades para realizar práticas alimentares corretas e os estilos de vida saudáveis. O objetivo final da aplicação desse instrumento validado será a utilização dos dados obtidos para identificar os pontos fracos para incentivar uma promoção e proteção da saúde da população alvo da pesquisa.

O instrumento consta de:

- Uma ficha antropométrica para valoração do Índice de Massa Corporal (IMC) e, portanto, o grau de obesidade. Aplicou-se o questionário aos consumidores com valores de IMC igual ou maior a $25 \mathrm{~kg} / \mathrm{m}^{2}$.

- Um formulário que para sua organização foi dividido em seções:

$$
\begin{aligned}
& \text { a - dados demográficos; } \\
& \text { b - dados de saúde; }
\end{aligned}
$$


c - dados sobre o uso e a interpretação das informações nutricionais da rotulagem dos alimentos.

O tempo máximo de preenchimento do instrumento é de 40 minutos, em média, de acordo com a prova feita no grupo focal.

Para as perguntas fechadas do formulário, utilizaram-se respostas de alternativas dicotômicas, tricotômicas e múltiplas.

Elaboraram, também, as instruções para a entrevista e um termo de consentimento de intervenção do entrevistado(anexos I e II). A ficha antropométrica e o formulário serão aplicados por contato direto, pois dessa forma aumenta-se a possibilidade de completar as respostas do instrumento em $100 \%$, pelo fato de poder esclarecer as dúvidas no momento de preenchimento do formulário.

A ficha antropométrica tem duas medições a serem feitas, que são peso e altura. Posteriormente realiza-se o cálculo do IMC que define, com o valor igual ou maior a $25 \mathrm{~kg} / \mathrm{m}^{2}$, os participantes no questionário sobre o comportamento do consumidor frente às informações da rotulagem nutricionais dos alimentos.

O formulário está integrado por 26 questões fechadas com diferentes alternativas que já foram descritas.

As variáveis que integram o instrumento são:

- Variáveis demográficas que caracterizam o consumidor;

- Variáveis de saúde;

- Variáveis de hábitos de compra, sobre o uso e percepção dos rótulos nutricionais de alimentos.

Com a continuação da elaboração do instrumento, efetuaram-se as validações do mesmo, conforme os passos enumerados:

1 - aplicação da técnica de juízes;

2 - aplicação das correções;

3 - aplicação ao grupo focal para análise semântica; e

4 - revisão final do instrumento. 


\subsubsection{Segunda etapa - Validação por técnica de juízes e aplicação do grupo focal}

A primeira etapa da validação foi a técnica de juízes. Para sua realização, a orientadora da monografia indicou cinco profissionais da área de rotulagem para opinar sobre o instrumento da pesquisa elaborado. A partir das sugestões dos juízes, foi modificado, principalmente quanto à linguagem usada para ser compreendida pelo público-alvo com alto ou baixo nível de escolaridade. Agregaram-se, também, duas questões sobre o entendimento dos termos usados nos rótulos de alimentos. O formulário foi enviado novamente para a validação final.

Imediatamente, foi aplicada a técnica de grupo focal para análise semântica do questionário. A etapa prévia foi a seleção dos integrantes do grupo focal, para isso se realizaram as determinações dos IMC dos participantes. Fizeram-se 14 determinações de IMC para selecionar 9 participantes moradores da Asa Norte e Asa Sul, do DF. A aplicação do grupo focal permite a coleta de dados de valores, percepções e crenças que vão possibilitar a correção final do instrumento de pesquisa. Durante a reunião foi avaliada a compreensão dos termos utilizados no instrumento, a compreensão das informações nutricionais dos rótulos e as sugestões de modificar ou acrescentar outros itens do tema em questão. Procurouse um local adequado para sua realização que teve uma duração de uma hora e meia. A dinâmica do grupo foi descontraída com uma interação fluente dos integrantes do grupo. O moderador do grupo evitou a dispersão natural do grupo aplicando um roteiro pré-feito sem fazer juízos de valor sobre os comentários dos participantes (Anexo III).

Segundo Oliveira e cols. (2000), nos estudos de natureza qualitativa se deve aplicar o seguinte roteiro:

- Apresentação por parte do moderador dos objetivos da reunião, da importância dos aportes dos integrantes no trabalho para aprimorar o instrumento, e em uma segunda etapa, coleta dos dados do entendimento e uso da informação nutricionais do público-alvo do estudo. No final, explicou-se aos participantes que os resultados obtidos tinham por objetivo promover uma redução dos índices de sobrepeso/obesidade da população alvo por meio do uso adequado das informações nutricionais dos rótulos de alimentos. Os integrantes também foram estimulados a apresentarem-se ao grupo (nome, idade, ocupação, etc.). 
- Leitura das instruções do preenchimento do instrumento.

- Leitura das perguntas do questionário e esclarecimento das dúvidas que possam ser geradas dessa leitura.

- Os integrantes do grupo preencheram o formulário.

- Também, os integrantes responderam anonimamente, por escrito, às seguintes perguntas do roteiro de discussão:

1 - Para você, o tema de pesquisa é importante? Explique o porquê.

2 - As perguntas do formulário são claras?

3 - Algum termo das perguntas foi difícil de ser compreendido?

4 - Você substituiria alguma palavra? Em que número de pergunta? Qual seria?

5 - O que você acha da quantidade de perguntas do formulário?

6 - Você excluiria ou acrescentaria alguma pergunta? Ou alguma outra sugestão para aperfeiçoar o formulário?

Por último, foi feita a discussão em grupo do formulário e das perguntas acima colocadas.

\section{RESULTADOS E DISCUSSÃO}

4.1. Etapa de concepção e elaboração do instrumento

A ficha antropométrica foi constituída por dados de identificação, dados antropométricos e o cálculo e valoração de IMC (AnexolV).

O formulário dessa primeira etapa (Anexo V), para aplicar no público-alvo foi constituído por 26 perguntas divididas em 3 corpos de pesquisa:

- dados de identificação composto por 6 perguntas;

- dados de saúde composto de 4 perguntas;

- dados de comportamento do consumidor frente à rotulagem nutricional composto por 16 perguntas.

O público-alvo do questionário foi integrado pelos consumidores adultos ( $>$ de 18 anos), com sobrepeso/obesidade usuários de uma clínica médica privada do DF.

4.2. Etapa de validação do instrumento pela técnica de juízes 
A técnica de juízes teve como finalidade analisar o conteúdo da ficha antropométrica e das perguntas do formulário e a linguagem utilizada. O instrumento foi analisado por cinco juízes, feitas as correções com as observações e sugestões, foi avaliado novamente e aprovado pelos juízes. A ficha antropométrica não teve modificações de nenhuma natureza.

As observações e sugestões basicamente foram algumas formas da linguagem utilizadas no formulário. Por exemplo: check- up foi mudado por avaliação médica, fonte de informação por meio de informação, rótulos dos alimentos por embalagens. O número de perguntas ficou em vinte e seis questões.

\subsection{Etapa de validação do instrumento pelo grupo focal}

Nesta etapa, o formulário foi submetido à análise semântica feita pelo grupo focal com características similares ao público-alvo da pesquisa. Previamente, fizeram-se quatorze medições do IMC dos possíveis integrantes do grupo focal, ficaram nove pessoas com as características requeridas de valor de IMC. O grupo estava integrado por seis mulheres e três homens de uma faixa etária entre os vinte e os cinqüenta e dois anos, sendo a média, trinta e seis anos. O nível de escolaridade foi nível médio (3) e nível superior (6), dividido em: 2 estudantes, 4 graduados, 2 com especialização e 1 com doutorado. O estado civil dividiu-se em: 6 com companheiros e 3 sem companheiro. A renda familiar oscilou de 8 a 60 salários mínimos.

Com respeito ao instrumento que preencheram os integrantes do grupo focal, obtiveram-se os seguintes resultados:

Pergunta 1: Para você, o tema de pesquisa é importante? Explique o porquê.

Todos identificaram o tema de importância relevante para orientar melhor as escolhas de alimentos para promover hábitos alimentares mais saudáveis. Também para esclarecer termos que não são familiares para o consumidor.

Perguntas 2: As perguntas do formulário são claras?

3: Algum termo das perguntas foi difícil de ser compreendido?

4: Você substituiria alguma palavra? Em que número de perguntas?

Todos os integrantes concordaram com a clareza das perguntas, dos termos utilizados, sem achar necessidade de mudar alguma pergunta ou termo. 
Pergunta 5 : O que você acha da quantidade de perguntas do formulário?

6: Você excluiria ou acrescentaria alguma pergunta do instrumento de pesquisa?

O grupo mostrou conformidade com o número de perguntas.

Em geral, a discussão do grupo realizou-se em torno da importância da informação nutricional dos rótulos de alimentos, do marketing enganoso de alguns produtos, por exemplo, a bebida láctea e o iogurte, que muitas vezes operam com embalagens muito similares e que, nutricionalmente falando, não são a mesma coisa. O grupo focal indicou que os termos "não contém", "livre de..", " aumentado teor de", " baixo teor de.." podem ser de difícil entendimento nas classes com baixo nível de instrução.

Outros exemplos que foram discutidos foram os chocolates diets indicados para dietas de emagrecimento, porque não têm açúcar, mas o valor calórico por porção é igual ou maior que nos chocolates normais pelo fato de acrescentar mais lipídeos para lograr a textura desejável em um chocolate. Também o fato de que a CocaCola light deveria ser diet, porque não contém açúcar. Então conclui-se que a credibilidade de algumas informações nutricionais dos rótulos de alimentos são duvidosas ou falsas e a defesa do consumidor deveria ser mais efetiva.

\section{Considerações Finais}

Cabe lembrar que a rotulagem é o meio pelo qual se estabelece um canal de comunicação entre empresas produtoras de alimentos e consumidores que desejam melhores informações sobre os produtos que compram. Entre outros objetivos, a regulamentação da rotulagem procura proteger os consumidores de declarações abusivas ou infundadas que possam induzi-los a erros. (ARAúJO E ARAúJO, 2001).

A importância crescente da rotulagem nutricional dos alimentos para a promoção de uma alimentação saudável e destacado em grande parte por estudos e pesquisas que envolvem a área de nutrição e sua relação com estratégias para a redução dos índices de sobrepeso/obesidade e doenças crônico-degenerativas.

O acompanhamento de dados estatísticos dos últimos 20 anos mostra-nos que a obesidade é umas das doenças que mais cresce no mundo, passando a ser 
uma preocupação de saúde pública. Atualmente, atinge mais de 30\% dos brasileiros e milhares desses são obesos mórbidos (REPETTO e cols., 2001).

O instrumento de pesquisa validado desse trabalho vai servir para a coleta de dados que permitam realizar um diagnóstico de situação dos conhecimentos e o uso adequado da rotulagem nutricional dos alimentos por parte do consumidor que já incorra em uma patologia alimentar como o sobrepeso/obesidade.

Os resultados da aplicação futura deste instrumento validado serão um subsídio para as indústrias de alimentos, para profissionais da saúde, para focar iniciativas visando melhorar o processo de comunicação da informação nutricional veiculada nas embalagens de alimentos.

A re-educação alimentar apresenta-se, atualmente, como a mais apropriada quando o objetivo preconiza o controle do sobrepeso/obesidade ou a melhora do estado geral e da saúde e, na prática, significa aprender a encarar a alimentação por um novo ponto de vista, escolhendo os alimentos adequados em quantidade e qualidade.

Esse trabalho pretende ser uma ferramenta para pesquisar os hábitos alimentares dos consumidores por meio do comportamento frente às informações nutricionais dos rótulos de alimentos. No futuro, baseados nos dados obtidos, serão úteis para propor mudanças nas escolhas de alimentos com o uso adequado da rotulagem de alimentos, pelo qual se produzirão uma melhoria na Qualidade de Vida dos consumidores.

A melhor ferramenta que temos para combater os erros alimentares é a informação. Cabe a todos, indústrias de alimentos, profissionais da saúde e ao governo trabalhar em conjunto para modificar o ambiente, de forma que ele apresente uma menor contribuição para o ganho de peso. Portanto, o conhecimento do uso das informações nutricionais dos rótulos de alimentos se revela como fundamental para mudar essa realidade que atinge uma porcentagem tão significativa no Brasil e no mundo.

Por meio desse presente trabalho, pode-se concluir que a elaboração de um instrumento de pesquisa validado para avaliar o comportamento do consumidor adulto com sobrepeso/obesidade, frente às informações nutricionais dos rótulos dos alimentos, vai possibilitar poder definir e aprofundar o estado dos conhecimentos do tema. Finalmente, o público-alvo poderá ter uma melhor defesa dos direitos como consumidor. 
REFERÊNCIAS BIBLIOGRÁFICAS

AGÊNCIA NACIONAL DE VIGILÂNCIA SANITÁRIA (ANVISA). Alimentos: Rótulo de Alimento. Rotulagem Nutricional. Disponível na internet em: www.anvisa.gov.br. Acessado em 10 de agosto de 2005.

AKUTSU, RITA. Apostila de Metodologia Científica, Centro de Excelência de Turismo, Universidade de Brasília, 2005.

ARAÚJO, A.C.M.F. e ARAÚJO, W.M.C. Adequação à Legislação Vigente da Rotulagem de Alimentos para Fins Especiais dos Grupos de Alimentos para Dietas com Restrição de Carboidratos e Alimentos para Dieta de Ingestão Controlada de Açúcares. Revista Higiene Alimentar, v.15, n. 52-70, mar. 2001.

BATISTA FILHO, M., RISSIN, A. A transição nutricional no Brasil: tendências regionais e temporais. Cadernos de Saúde Pública, v. 19 (sup.1), p. S 181 -S 191, 2003.

BENGMARKS, S. Ecoinmunonutrition: a challenge for the third millenium. $N$ 1497/80:563-572, 1998.

BERNARDI, F. Comportamento de restrição alimentar e obesidade. Revista de Nutrição, Campinas, 18 (1): 85-93, jan./fev., 2005.

BRASIL. Ministério da Agricultura e do Abastecimento. Portaria $n^{\circ} 371$ de 04 de setembro de 1997. Aprova regulamento técnico para Rotulagem de Alimentos Embalados. Diário Oficial da União, Brasília, 08.09.1997.

BRASIL. Ministério da Justiça. Lei n 8.078, 11.09.1990. Dispõe sobre a proteção do consumidor e dá outras providências. Disponível na Internet em www.mj.gov.br/DPDC/serviços?legislaçao/cdc.htm. Acessado em 10.08.05. 
BRASIL. Ministério da Saúde. Portaria $n^{\circ} 23$ de 04.05.1988. Aprova normas sobre alimentos dietéticos. Agência Nacional de Vigilância Sanitária (ANVISA). Diário Oficial da União, Brasília, 04.04.1988.

BRASIL. Ministério da Saúde. Portaria SVS n²7 de 13.01.1998. Aprova Regulamento Técnico referente à Informação Nutricional Complementar. Agência Nacional de Vigilância Sanitária (ANVISA). Diário Oficial da União, Brasília,13.01.1998.

BRASIL. Ministério da Saúde. Portaria SVS n² 29 de 30.03.1998. Aprova Regulamento técnico para fixação de identidade e qualidade de alimentos para fins especiais. Agência Nacional de Vigilância Sanitária (ANVISA). Diário Oficial da União, Brasília, 30.03.1998.

BRASIL. Ministério da Saúde. Portaria SVS no 30 de 31.01.1998. Aprova Regulamento Técnico para fixação de identidade e qualidade de alimentos para controle de peso. Agência Nacional de Vigilância Sanitária (ANVISA). Diário Oficial da União, Brasília, 31.01.1998.

BRASIL. Ministério da Saúde. Portaria SVS no 30 de 31.01.1998. Aprova Regulamento Técnico para fixação de identidade e qualidade de alimentos adicionados de nutrientes essenciais. Agência Nacional de Vigilância Sanitária (ANVISA). Diário Oficial da União, Brasília 13.01.1998.

BRASIL. Ministério da Saúde. Portaria SVS no 33, de 30.03.1998. Aprova Regulamento Técnico à Ingestão Diária Recomendada (IDR) para proteínas, vitaminas e minerais. Agência Nacional de Vigilância Sanitária (ANVISA). Diário Oficial da União, Brasília 30.03.1998.

BRASIL. Ministério da Saúde. Portaria SVS no 38 de 15.01.1998. Aprova Regulamento Técnico para Fixação de Identidade e Qualidade de Adoçantes de 
Mesa. Agência Nacional de Vigilância Sanitária (ANVISA). Diário Oficial da União, Brasília, 15.01.1998.

BRASIL. Ministério da Saúde. Portaria SVS no 41 de 14.01.1998. Aprova Regulamento Técnico para Rotulagem Nutricional de Alimentos Embalados. Agência Nacional de Vigilância Sanitária (ANVISA). Diário Oficial da União, Brasília, 21.01.1998.

BRASIL. Ministério da Saúde. Resolução RDC no 40 de 21.03.2001. Aprova Regulamento Técnico para Rotulagem Nutricional Obrigatória de Alimentos e Bebidas Embalados. Agência Nacional de Vigilância Sanitária (ANVISA). Diário Oficial da União, Brasília, 21.03.2001.

BRASIL. Ministério da Saúde. Resolução RDC no 259 de 20.09.2002. Aprova Regulamento Técnico para Rotulagem de Alimentos Embalados. Agência Nacional de Vigilância Sanitária (ANVISA). Diário Oficial da União, Brasília, 23.09.2002.

BRASIL. Ministério de Saúde. Resolução RDC n³60 de 23.12.03. Aprova Regulamento Técnico Sobre Rotulagem Nutricional de Alimentos Embalados. Agência Nacional de Vigilância Sanitária (ANVISA). Diário Oficial da União, Brasília, 26.12.2003.

CÂNDIDO, L.M.B. e CAMPOS, A. M. Alimentos para fins especiais: dietéticos. São Paulo, Livraria Varela, 1995.

COORDENAÇÃO GERAL DA POLÍTICA DE ALIMENTAÇÃO E NUTRIÇÃO (CGPAN). A promoção de alimentação saudável como instrumento de prevenção e combate ao sobrepeso e obesidade, 2004. 
COITINHO, D., MONTEIRO, C.A., POPKIN, B.M. What Brazil is doing to promote health diets and actives lifestyles. Public Health Nutrition. v. 5, n. 1A, 263-267, 2002.

COPPINI,L. Z. ;WAITBERG, A.L. Nutrição oral, enteral, e parenteral na prática clínica. In: Obesidade: Abordagem Dietética. 3ª ed. São Paulo: Atheneu, 2000. v. 2. Cap 65, p 1023-1035.

DUTRA DE OLIVEIRA, MARCHINI, J.S. Ciências Nutricionais. São Paulo: Sarvier, 1998.

FELIPE, M. R., MEZADRI, T., CALIL, J., KUSTER, M.K., MAFRA, G.C. Rotulagem de Alimentos: o comportamento do consumidor usuário de supermercados do Balneário Camboriú/SC. Revista Higiene Alimentar. v. 17, nº 111, p. 49-57, 2003. FERRAZ, R.G. Comportamento do consumidor frente à informação nutricional em rotulagem de produtos alimentícios - Um estudo no varejo de Belo Horizonte/MG. Dissertação de mestrado em Ciência e Tecnologia de Alimentos. Universidade Federal de Viçosa, 2001.

FLANDRIN J. L.; MONTANARI, M. História da Alimentação. São Paulo:Estação Liberdade, 1998.

FREITAS,H., OLIVEIRA, M., SACCOL,A Z., MOSCAROLA, J. O método de pesquisa survey. Revista de administração.São Paulo v.35, n.3, p.105-112, 2000. FUNDAÇÃO INSTITUTO BRASILEIRO DE GEOGRAFIA E ESTATÍSTICA (IBGE). Síntese de indicadores sociais 2002. Departamento de população e indicadores sociais - RJ, 2003.

FUNDAÇÃO INSTITUTO BRASILEIRO DE GEOGRAFIA E ESTATÍSTICA (IBGE). Censo Demográfico - 2000. Disponível na internet em http://www.ibge.gov.br acessado em 10.08.2005. 
GARCIA, R. W. D. A. A culinária subvertida pela origem terapêutica: um modelo de se relacionar com a comida. In Simpósio Sul- Brasileiro de alimentação e nutrição: história, ciência e arte. Anais... Florianópolis, UFSC, 2000. p. 13-16.

HALPERN, A. Cirurgia da obesidade. In: Fisiopatologia da obesidade, 1 ed. São Paulo: Atheneu, 2000. Cap. 2 P. 9-12.

INSTITUTO NACIONAL DE METROLOGIA (INMETRO). Programa de análise de produtos: produtos diets e lights. Disponível na internet em www.inmetro.gov.br/consumidor.produtos acessado em 10.08.2005.

LESSA, M. MINISTÉRIO DA SAÚDE. Obesidade é considerada uma epidemia mundial. Disponível na internet em www.saúde.gov.br acessado em 10.08.2005.

MINISTÉRIO DA SAÚDE. AGÊNCIA NACIONAL DE VIGILÂNCIA SANITÁRIA UNIVERSIDADE DE BRASÍLIA. Rotulagem nutricional obrigatória: Manual de orientação aos consumidores. 2002.

MINISTÉRIO DA SAÚDE. AGÊNCIA NACIONAL DE VIGILÂNCIA SANITÁRIA UNIVERSIDADE DE BRASÍLIA. Rotulagem nutricional obrigatória: Manual de orientação às indústrias, 2004.

MARTINS, C. ; ABREU, S. S. Pirâmide de Alimentos: manual do educador. Curitiba: Nutroclínica, 1997.

MORON ,M. A. M. Concepção, Desenvolvimento e Validação de Instrumentos de Coleta de Dados para Estudar a Percepção do Processo Decisório e as diferenças culturais. Dissertação de Mestrado. Escola de Administração. Universidade Federal do Rio Grande do Sul, 1998.

MIYAZAKI, E. Rotulagem de alimentos e bebidas. Centro de Excelência em Turismo da Universidade de Brasília, 2005. 
MONTEIRO, C. A., MONDINI, L., DE SOUZA, A. L., POPKIN, B. M. The nutrition transition in Brazil. European Journal of Clinical Nutrition, v. 49 p. 105-113, 1995. NEGRATO, C. A. Obesidade, um problema de saúde pública. Revista Racine, p. 18-33, 2003.

ORNELLAS, L. H. Técnica Dietética: seleção e preparo de alimentos. 6. ed. São Paulo:Atheneu, 1995.

POPKIN, B. M. The nutrition transition and obesity in the developing world. The Journal of Nutrition, v. 131, n. 3, p. 871S-873S, 2001.

SHANK, F. R. , CARSON, K. L. The regulatory environmental past and the future- incentive or impediment to developments in food science and technology: a perspective from FDA. Critical Reviews in Food Science and Nutrition, Boca Raton, v.34, n.2, p.207-214, Mar., 1994.

REPETTO G.; CORÀ MOTIN, C.; CASAGRANDE, D.;MARCHESE, C. Tratamento Clínico e Cirúrgico da Obesidade Mórbida. Nutrição em Pauta. Ano IX, N48, 2001.

RICHARDSON, R. J. Pesquisa social: métodos e técnicas. São Paulo:Atlas, 1985. RIZZOLO, A., assessora técnica da Coordenação Geral de políticas de Alimentação e Nutrição do Ministério da Saúde: depoimento (21/10/03) Ministério da Saúde. Obesidade Infantil. Disponível na Internet em <www.saude.gov.br>. Acessado em 10/08/05.

SANTOS NAHUZ, C. Manual de normalização de monografias - 3.ed. ver. atual. e ampl. - São Luiz, 2002.

TAGLE, M. A. Cambios en los patrones de consumo alimentario en América Latina. Arch Latinoamericanos de Nutrición 38(3):751765, 1988. 


\section{ANEXOS}

\section{Anexo I. Instruções para abordar o entrevistado}

1. Apresentação do entrevistado e o motivo da pesquisa.

Eu sou nutricionista, estou realizando uma pesquisa na UnB sobre o entendimento e o uso dos consumidores frente às informações nutricionais dos rótulos dos alimentos em relação ao desenvolvimento de sobrepeso e obesidade. Para isso, necessitamos de sua colaboração com a realização de uma ficha antropométrica em que eu vou pesar e medir você e imediatamente o preenchimento das questões desse formulário. Os dados serão de grande utilidade para incentivar a promoção de hábitos alimentares saudáveis e uma melhor defesa do consumidor. Agradeço sua colaboração, muito obrigada.

2. Realização da ficha antropométrica e o formulário.

3. Finalização da entrevista: agradecimento por sua cooperação com a pesquisa. 


\section{Anexo II. Termo de consentimento.}

Universidade de Brasília, Centro de Excelência em Turismo

Curso de Especialização em Qualidades dos Alimentos

Responsável: Nta. Alicia Mônica Lorieto Díaz

Orientadora: Profa. Dra. Wilma Araújo

Por o presente termo de consentimento, declaro haver sido informado da finalidade dessa pesquisa, que versa sobre o comportamento do consumidor frente às informações nutricionais das embalagens dos alimentos que será realizada em três hospitais privados do DF, Brasília . Aceito minha participação livre e espontânea para contribuir com o dados que eu possa fornecer, os quais terão garantia de sigilo por parte dos pesquisadores.

Brasília, de de 


\section{Anexo III. Roteiro do moderador}

1. Instruções de preenchimento individual do questionário, prévia seleção dos integrantes por valoração do IMC.

2. Prévia leitura do questionário.

3. Depois de completar o questionário, cada integrante do grupo focal responderá seis perguntas abertas e anônimas já mencionadas na página do trabalho.

4. Discussão em grupo do questionário e as seis perguntas complementares. 
ANEXO IV

INSTRUMENTO DE AVALIAÇÃO DO COMPORTAMENTO DO CONSUMIDOR ADULTO COM SOBREPESOIOBESIDADE FRENTE ÀS INFORMAÇÕES NUTRICIONAIS DOS RÓTULOS DE ALIMENTOS.

Ficha antropométrica para deteminação do IMC

Dados de identific ação

Nome:

Idade:

Sexo:

Dados a ntropométric os

Peso:

Altura:

Cálculo e valoração de IMC

$\mathrm{IMC}=\mathrm{kg} / \mathrm{m}^{2}$

\begin{tabular}{|c|c|c|}
\hline IMC kg/m & Classific açã o & valor obtido \\
\hline $18-24,9$ & nomopeso & \\
\hline $25-29,9$ & sobrepeso & \\
\hline $30-34,9$ & obesidade G 1 & \\
\hline $35-39,9$ & obesidade G2 & \\
\hline 40 ou ma is & obesidade G3 & \\
\hline
\end{tabular}

O questioná rio só será a plicado em pessoas com IMC > ou $=25 \mathrm{~kg} / \mathrm{m}^{2}$ 


\section{Anexo V}

Formulário de avaliação do comportamento do consumidor com sobrepeso/obesidade frente às informações nutricionais dos rótulos de alimentos

A - Dados de identific ação

1. Sexo:

2. Idade:

3. Profissão/ocupação:

4. Escolaridade:
4a. sem esc olaridade
4e. Graduação
$4 b .1^{a}$ à $4^{a}$ série
4f. Especializa ção
4c. $5^{a}$ à $8^{a}$ série
4g. Mestrado
4d. $2^{\circ}$ grau
4h. Doutorado

5. Esta do civil:

5a. com companheiro

5b. sem compa nheiro

6. Renda familiar:

6a. < 5 salários mínimos

6b. 5 - $10 \mathrm{sm}$

6c. $11-15 \mathrm{sm}$

6d. $16-20 \mathrm{sm}$

6e. >20 salários mínimos

B - Dados de saúde

1. Com que freqüência você realiza uma avaliação médica (check-up)? 1a. a cada 6 meses

1b. a cada 1 ano

1c. a cada 2 anos

1d. só vai ao médico quando se acha doente

2. Você se preocupa em ter uma alimentação saudável, ou seja, escolher a limentos os ma is na tura is possíve is (frutas, horta liça s, grã os, a limentos sem conservantes, nem corantes a rtificiais), varia dos, com ma is a limentos de origem vegetal que de origem a nimal, que ajudem a não ter doenças? 2a. sempre $2 b$. às vezes 
2c. nunca

3. Você tem conhecimento de doenças diagnosticadas (que o médico declarou) na família que necessitem de uma dieta específica ou seleção de a limentos específic os?

3a. não $3 b . \operatorname{sim} 3$. especific $a r$

4. Qual é seu meio de informação sobre alimentação ou dieta?

4a. médico

4b. nutric io nista

4c. mídia (tv, rádio, jomal, revista, intemet)

$4 d$. outras (especific ar)

C - Dados de comportamento do consumidor frente à rotulagem nutric ional

1. Com que freqüência você faz as compras de alimentos para sua casa?

1a. ra ramente

$1 b$. às vezes

1c. sempre

1d. nunca

2. Você lê as informa ções nutric iona is nas emba lagens a ntes de escolher um produto?

2a. $\operatorname{sim}$

2b. não

2c. às vezes

3. Os temos usados nas embalagens de alimentos são de fácil compreensão para você?

3a. $\operatorname{sim}$

3b. não

4. Mencione os termos das informações nutriciona is das embalagens de a limentos dos qua is você não conhece o significado:

5. Você acredita nas informações contidas nas embalagens dos a limentos?

5a. sim

5b. não

$5 c$. às vezes 
6. Escolha três fatores de maior para menor importância que influenciam em sua decisão na compra dos alimentos (o entrevistador vai colocar 1 , 2 e 3 nos itens indic a dos por o entrevista do, a pós sua leitura)

6a. preço

6b. qualidade nutricional (lista de ingredientes, conteúdo de nutrientes)

6c. marca

6d. praticidade

6e. sabor, a roma, cor

6f. se são produtos orgânicos (sem agrotóxicos, sem conservantes químicos)

6g. estética da embalagem (cores, design)

7. Você lê a lista de ingredientes que compõem o produto?

7a. sim

7b. não

7c. às vezes

8. Você lê o prazo de validade do produto?

8a. sim

8b. não

$8 c$. às vezes

9. Esc olha três a tributos das informa ções nutriciona is dos rótulos que você mais lê no momento da compra:

9a. valor calórico

9b. carboidratos

9c. proteínas

9d. gorduras tota is

9e. gorduras satura das

9f. colesterol

9g. fibra alimentar

9h. sódio

9i. ferro

9j. cálcio

$9 \mathrm{k}$. vitaminas

9l. nenhuma

10. O que você faria para selecionar alimentos ricos em cálc io ou fibras, a partir da informação dos rótulos?

10a. leria na coluna de percentual de valor diário (\% VD) o valor desse nutriente presente nas informações nutricionais

10b. simplesmente leria os temos das embalagens como fonte de cálcio ou fibrasou alto teor de cálcio

10c. não saberia

11. Para você, os temos light e diet signific am: 
11a. a mesma coisa

11b. diet significa isento de algum nutriente (exemplo: sem açúcar) e light significa que tem o valor reduzido no mínimo $25 \%$ com relação ao a limento original

11c. diet é um produto para diabéticos e light é um produto para quem quer emagrecer.

11d. não sabe

12. Com que freqüência você seleciona alimentos com valores reduzidos ou livres de calorias, açúcar, sódio, gorduras ou colesterol :

12a. sempre

$12 \mathrm{~b}$. às vezes

12c. nunca

13. Como você considera o termo "não contém" ou "livre de". Por exemplo, "não contém sódio":

13a. que o alimento não contém nenhuma quantida de do nutriente $13 \mathrm{~b}$. que o a limento pode ter qua ntida des insignific antes do nutriente 13c. não sabe

14. Para você o que significa "aumentado teor de". Por exemplo, "aumentado valor de vitamina A":

14a. que é uma característica do a limento natural

14b. que é uma adição do nutriente que fizera $m$ a o alimento natural

14c. não sabe

15. O a limento que tem "ba ixo teor de açúcar" signific que é:

15a. light

15b. diet

15c. nenhuma das respostas anteriores

15d. não sabe

16. Qual das expressões a seguir significa que o alimento contém maior quantidade de um nutriente?

16a. fonte de

16b. alto teorde

16c. não sabe 